\title{
Aknede Diğer Kozmetolojik Yöntemler
}

\section{Doç. Dr. Filiz Topaloğlu Demir}

İstanbul Medipol Üniversitesi Tıp Fakültesi, Deri ve Zührevi Hastalıklar Anabilim Dalı, İstanbul, Türkiye

Öz

Bu bölümde, aknede, nodülokistik lezyonların tedavisinde uzun yıllardır kullanılan ve kullanılmaya devam edilen intralezyonel kortikosteroid uygulamasına ve komedon ekstraksiyonu gibi basit girişimsel yöntemlere ek olarak skar tedavisinde yeri olan mikrodermabrazyona, püstüler ve yüzeyel kistik lezyonların tedavisinde kullanılan ve günümüzde akne tedavisinde pek tercih edilmeyen kriyoterapiye, komedon tedavisinde yeri olan elektrokoterizasyona ve özellikle atrofik akne skarlarında kullanılan cerrahi işlemlere kısaca değinilmiştir.

Anahtar Kelimeler: Akne, intralezyonel kortikosteroid uygulaması, fiziksel tedavi yöntemleri

\begin{abstract}
This section briefly covers the intralesional corticosteroid practice, which has been used for many years in the treatment of nodulocystic lesions in acne, and some simple interventional methods such as pore extraction, as well as microdermabrasion used to treat scars, cryotherapy to treat pustular and superficial cystic lesions, which is not preferred today for acne treatment, electrocauterization used to treat plugged pores, and surgical procedures to treat atrophic acne scars in particular.

Keywords: Acne, intralesional corticosteroid administration, physical therapy methods
\end{abstract}

\section{Giriş}

Intralezyonel kortikosteroid (ILKS) ve komedon ekstraksiyonu gibi basit girişimsel yöntemler akne tedavisinde yardımcı tedaviler olarak uzun yıllardan beri kullanılmaktadır. Bu bölümde bu eski fiziksel tedavi yöntemlerine ek olarak mikrodermabrazyon, kriyoterapi, elektrokoterizasyon ve cerrahi işlemler ele alınmıştır.

\section{Intralezyonel kortikosteroid uygulaması}

Skar oluşumunu önlemek amacıyla, hızlı yanıt istenen nodülokistik akne lezyonlarında sistemik izotretinoin veya antibiyotiklere ek olarak kullanılmaktadır. Kolay bir uygulama olması, maliyetinin düşük olması, yan etkilerinin az olması nedeniyle klinik pratikte klinisyenler tarafından sıklıkla tercih edilen, etkili bir tedavi yöntemdir ${ }^{1}$. Çoğu akne nodülünü 48 ila 72 saatte düzeltir². Ağrılı olabilir ve deride atrofiye yol açabilir ${ }^{3}$. Triamsinalon asetonid, en sık kullanılan ilaçtır. Steril normal saline solüsyonu ile dilüe edilir, en yaygın kullanılan iki dilüsyon 5 veya $2,5 \mathrm{mg} / \mathrm{mL}$ 'dir. Hastanın yanıtına ve lezyonun karakterine göre, edinilen deneyime uygun olarak mümkün olan en küçük konsantrasyonlarda enjekte edilmelidir ${ }^{4}$. Atrofi riski nedeniyle intralezyonel enjeksiyonlarda $5 \mathrm{mg} / \mathrm{mL}^{\prime}$ nin üzerindeki kontsantrasyonlarda kullanımı önerilmez ${ }^{5}$.

Akne pilosebasöz ünitenin bir hastalığı olduğu için, deride atrofi riskini, ağrıyı ve kanamayı azaltmak için kortikosteroid, 30 gauge insülin enjektörü ile gerekirse büyüteç yardımı ile

Yazıșma Adresi/Address for Correspondence: Doç. Dr. Filiz Topaloğlu Demir

İstanbul Medipol Üniversitesi Tip Fakültesi, Deri ve Zührevi Hastalıklar Anabilim Dall, İstanbul, Türkiye

E-posta: filizsvet@yahoo.com ORCID: orcid.org/0000-0002-2049-1316

C Telif Hakkı 2020 Deri ve Zührevi Hastalılar Derneği

Türkderm - Türk Deri Hastalıkları ve Frengi Arșivi, Galenos Yayınevi tarafından basılmıștır. 
kontrol edilerek porun içine uygulanmalıdır ${ }^{6}$. Derin enflame lezyonlarda aspirasyonu gerekli olabilir. Bu durumda lezyonun dibinden aspire edilmesi ve sonrasında steroidin enjekte edilmesi önerilmektedir?

ILKS tedavide kortikosteroidlere ek olarak antibiyotikler de kullanılmaktadır. ILKS'nin linkomisin ile kombinasyonun iLKS'nin yalnız kullanımından daha etkili olduğu bildirilmiştir. Kombinasyon tedavisinin etkinliği, yalnızca steroidlerin anti-enflamatuvar etkisi ve linkomisinin antibakteriyel etkisine değil, aynı zamanda linkomisinin immünomodülatör etkisine de bağlanmıştır8. ILKS'nin akne tedavisinde kullanılabilen diğer antibiyotiklerle kombine kullanımına dair yeterli veri yoktur.

\section{Komedon ekstirpasyonu}

Açık ve kapalı komedonlar, bir komedon ekstraktörü, ince bir iğne veya sivri uçlu bir bıçakla (kapalı komedonları açmak için) mekanik olarak çıkarılabilir. Hem yapılan işlemi kolaylaştırmak hem de yeni komedon oluşumunu önlemek için mekanik ekstraksiyondan önce bir topikal retinoid uygulanabilir. Çok sayıda komedonu olan hastalarda, oral izotretinoin tedavisine başlamadan önce komedonların boşaltılması enflamatuvar alevlenmeleri önlemek ve nadir bir olay olan tedavi sırasındaki akne fulminansın tetiklenmesinin önüne geçmek için çok önemlidir ${ }^{7,9}$. Isslem sonrası deri anti-enflamatuvar veya antimikrobiyal bir ajanla tedavi edilmelidir ${ }^{10}$.

Yetersiz ekstraksiyon, doku hasarı ve boşalan lezyonun yeniden dolması tedavinin dezavantajlarını oluşturur ${ }^{11}$.

\section{Mikrodermabrazyon}

Mikrodermabrazyon, alüminyun oksit kristalleri ve vakum yardımı ile stratum korneum tabakasının soyulması işlemidir. Başlangıçta akne skarlarının tedavisinde kullanılan bir uygulama olmakla birlikte, sonrasında antiaging tedavisinde ve pigmentasyon bozukluklarında da kullanılan popüler bir uygulama olmuştur ${ }^{12}$. Akne skarlarındaki etkisi, tekrarlayan uygulamalar sonrasında ortaya çıkan dermal fibroblastların ve epidermal yenilenmenin uyarılmasıdır ${ }^{13}$. Yağlı deri ve dilate porların tedavisinde de kullanılmaktadır ${ }^{14}$. Aktif akne tedavisinde etkinliğine dair yeterli veri yoktur. Akne tedavileri ile kombine kullanılabilir. Foliküler tıkaçları ve hiperkeratozu ortadan kaldırarak etki sağlar ${ }^{15}$.

Mikrodermabrazyon ayrıca fotodinamik tedavi öncesinde olduğu gibi topikal olarak uygulanan ilaçların emilimini veya ışı̆̆ın epidermise penetrasyonunu artırmak için de kullanılabilir ${ }^{16-18}$.

\section{Elektrocerrahi}

Elektrik enerjisi kullanılarak dokuda termal hasar oluşturma yoluyla etkili olan bu tedavi yöntemi özellikle $>1,5 \mathrm{~mm}$, çok sayıda açık ve kapalı komedonu olan hastalarda kullanılabilir ${ }^{19-22}$. Akne tedavisinde kullanılan elektrocerrahi uygulama yöntemleri, elektrokoterizasyon ve elektrofulgurasyondur ${ }^{19,20}$. Büyük komedonların (>1 mm) tedavisinde elektrokoterizasyon elektrofulgurasyondan daha etkili olurken küçük lezyonlarda etkinlikleri benzerdir. Kapalı komedonların tedavisinde elektrofulgurasyon, topikal tretinoinden daha başarılı bulunmuştur ${ }^{19}$. Elektrokoterizasyonun, immün sistemi uyararak komedonun elimine edilmesine yol açarak veya makro komedonların içeriğinin deri yüzeyine boşalması için bir yol oluşturarak etkili olduğu düşünülmekle birlikte akne tedavisindeki kesin etki mekanizması bilinmemektedir ${ }^{20,21}$.

\section{Kriyoterapi}

Kronik fluktuan nodüler lezyonların sıvı azot ile yüzeyel bir şekilde dondurulması lezyonların rezolüsyonunu hızlandır. Etkinlik; yüzeysel kistik lezyonlarda en yüksek olup etki lezyon derinleştikçe azalır. Her biri 15'er saniye olmak üzere iki donma/çözme döngüsü önerilmektedir. Bu yöntem fibrotik kist duvarında nötrofil kemotaksisi ile sonuçlanan soğuk hasarına yol açarak etki gösterir. Nötrofillerden salınan proteazlar kist duvarını tahrip ederek iyileşmeye olanak sağlar ${ }^{23}$. Kriyoterapi, yüzeyel kistik lezyonlara ek olarak püstüler lezyonların tedavisinde de etkilidir. Komedonlarda ve papuler lezyonlarda kullanılması önerilmez ${ }^{4}$. Ağrıı bir tedavi yöntemi olması, pigmentasyon bozukluklarına ve skara yol açma riski kullanımını sınırlandırmaktadı²4.

\section{Cerrahi işlemler}

Punch eksizyon, punch elevasyon (punch eksizyon ve greftleme) ve subkütanöz insizyon olarak da bilinen subsizyon, atrofik akne skarlarının tedavisinde kullanılan başlıca cerrahi işlemlerdir?

\section{Sonuç}

Akne tedavisinde hızlı etkinlik elde etmek ve skarla iyileşme riskini minimuma indirmek için ILKS uygulaması ve komedon ekstirpasyonu başta olmak üzere fiziksel tedavi yöntemlerinin aknenin standart tedavisine eklenmesi tedavi başarısını artırmaktadır. Akne lezyonuna göre şeçilmesi önerilen fiziksel tedavi yöntemi Tablo 1'de özetlenmiştir.

Tablo 1. Akne lezyonuna göre kullanılması önerilen fiziksel tedavi yöntemi

\begin{tabular}{|l|l|}
\hline Intralezyonel kortikosteroid & Akne lezyonu \\
\hline Komedon ekstraksiyonu & Enflamatuvar lezyonlar (nodül ve kist) \\
\hline Mikrodermabrazyon & Açık ve kapalı komedonlar \\
\hline Elektrocerrahi & Akne skarları, dilate porlar \\
\hline Kriyoterapi & Açık ve kapalı komedonlar \\
\hline Cerrahi işlemler & Yüzeysel kistik lezyonlar ve püstüller \\
\hline Komedon ekstraksiyonu & Akne skarları \\
\hline
\end{tabular}

\section{Kaynaklar}

1. Rebello D: Intralesional triamcinolone acetonide in skin diseases other than psoriasis. Br J Dermatol 1962;74:358-60.

2. Levine $\mathrm{R}$, Rasmussen J: Intralesional corticosteroids in the treatment of nodulocystic acne. Arch Dermatol 1983;119:480-1.

3. Newman, MD, Bowe WP, Heughebaert C, Shalita AR: Therapeutic considerations for severe nodular acne. Am J Clin Dermatol 2011;12:7-14.

4. Goldman L: Reactions following intralesional and sublesional injections of corticosteroids. JAMA 1962;182:613-6.

5. Mehta N: Intralesional therapy. Textbook and atlas of dermatosurgery and cosmetology. Savant SS, Shah RA, Gore D, editors. Mumbai: ASCAD; 1998:91-2.

6. Lee SJ, Hyun MY, Park Kim BJ: A tip for performing intralesional triamcinolone acetonide injections in acne patients. J Am Acad Dermatol 2014;71:127-8.

7. Dreno B: Acne: Physical treatment. Clin Dermatol 2004;22:429-33.

8. Mahajan BB, Garg G: Therapeutic efficacy of intralesional triamcinolone acetonide versus intralesional triamcinolone acetonide plus lincomycin in the treatment of nodulocystic acne. Indian J Dermatol Venereol Leprol 2003;69:217-9.

9. Wise EM, Graber EM: Clinical pearl: Comedone extraction for persistent macrocomedones while on isotretinoin therapy. I Clin Aesthet Dermatol 2011:4:20-1.

10. Steventon K: Expert opinion and review article: the timing of comedone extraction in the treatment of premenstrual acne-A proposed therapeutic approach. Int J Cosmet Sci 2011;33:99-104. 
11. Gollnick $H$, Cunliffe $W$, Berson $D$, et al: Management of acne: a report from a Global Alliance to Improve Outcomes in Acne. J Am Acad Dermatol 2003;49:1-37

12. Tsai R, Wang $\mathrm{C}$, Chan $\mathrm{H}$ : Aluminum oxide crystal microdermabrasion. A new technique for treating facial scarring. J Invest Dermatol 2003;121:1118-25.

13. Shpall R, Beddingfield F, Watson D, Lask GP: Microdermabrasion:a review. Facial Plast Surg 2004;20:47-50.

14. Hernandez-Perez E, Ibiett E: Gross and microscopic findings in patients undergoing microdermabrasion for facial rejuvenation. Dermatol Surg 2001;27:637-40.

15. Lloyd JR: The use of microdermabrasion for acne: A pilot study. Dermatol Surg 2001;27:329-31.

16. Lee WR, Shen SC, Kuo-Hsien W, Hu C-H, Fang J-Y: Lasers and microdermabrasion enhance and control topical delivery of vitamin C. J Invest Dermatol 2003;121:1118-25.

17. Nestor M, Gold M, Kauvar A, et al: The use of photodynamic therapy in dermatology: results of a consensus conference. J Drugs Dermatol 2006;5:140-54.
18. Goldberg DJ, Russell BA: Combination blue ( $415 \mathrm{~nm}$ ) and red (633 nm) LED phototherapy in the treatment of mild to severe acne vulgaris. J Cosmet Laser Ther 2006;8:71-5.

19. Bottomley WW, Yip J, Knaggs $H$, Cunliffe WC: Treatment of closed comedones-comparisons of fulguration with topical tretinoin and electrocautery with fulguration. Dermatology 1993;186:253-7.

20. Kaminsky, A: Less common methods to treat acne. Dermatology 2003;206:68-73

21. Thomson KF, Goulden V, Sheehan-Dare R, Cunliffe WC: Light cautery of macrocomedones under general anaesthesia. Br J Dermatol 1999; 141:595-

22. Pepall LM, Cosgrove MP, Cunliffe WJ: Ablation of whiteheads by cautery under topical anaesthesia. Br J Dermatol 1991;125:256-9.

23. Graham GF: Cryotherapy against acne vulgaris yields good to excellent results. Dermatol Prac 1972;5:13-5.

24. Taub AF: Procedural Treatments for Acne Vulgaris. Dermatol Surg 2007:33:1005-26 